\title{
Verzeichnis textlicher Abkürzungen
}

\begin{tabular}{|c|c|c|c|}
\hline aalem. & altalemannisch & els. & elsässisch \\
\hline abair. & altbairisch & EN. & Eigenname \\
\hline adän. & altdänisch & engl. & englisch \\
\hline Adj. & Adjektiv & erzgeb. & erzgebirgisch \\
\hline adj. & adjektivisch & estn. & estnisch \\
\hline adt. & altdeutsch & europ. & europäisch \\
\hline Adv. & Adverb & & \\
\hline $\begin{array}{l}\text { adv. } \\
\text { aengl. }\end{array}$ & $\begin{array}{l}\text { adverbial } \\
\text { altenglisch }\end{array}$ & f. & feminin \\
\hline aeurop. & alteuropäisch & fahd. & frühalthochdeutsch \\
\hline afrk. & altfränkisch & finn. & finnisch \\
\hline afrz. & altfranzösisch & fläm. & flämisch \\
\hline afries. & altfriesisch & FlN. & Flurname \\
\hline agerm. & altgermanisch & FN. & Familienname \\
\hline agriech. & altgriechisch & frankoprov. & $\begin{array}{l}\text { frankoprovenzalisch } \\
\text { friesisch }\end{array}$ \\
\hline $\begin{array}{l}\text { ags. } \\
\text { ahd. }\end{array}$ & $\begin{array}{l}\text { angelsächsisch } \\
\text { althochdeutsch }\end{array}$ & frk. & fränkisch \\
\hline aisl. & altisländisch & frmhd. & frühmittelhochdeutsch \\
\hline Akk. & Akkusativ & frnhd. & frühneuhochdeutsch \\
\hline aksl. & altkirchenslawisch & frz. & französisch \\
\hline $\begin{array}{l}\text { Akt. } \\
\text { alem. }\end{array}$ & $\begin{array}{l}\text { Aktiv } \\
\text { alemannisch }\end{array}$ & Fut. & Futur \\
\hline altung. & altungarisch & gäl. & gälisch \\
\hline and. & altniederdeutsch & gall. & gallisch \\
\hline $\begin{array}{l}\text { antrk. } \\
\text { anl. }\end{array}$ & $\begin{array}{l}\text { altniedertränkisch } \\
\text { altniederländisch }\end{array}$ & gallorom. & galloromanisch \\
\hline anord. & altnordisch & $\begin{array}{l}\text { Gen. } \\
\text { germ }\end{array}$ & $\begin{array}{l}\text { Genitiv } \\
\text { germanisch }\end{array}$ \\
\hline Aor. & Aorist & got. & gotisch \\
\hline $\begin{array}{l}\text { apoln. } \\
\text { aprov. } \\
\text { arab. }\end{array}$ & $\begin{array}{l}\text { altpolnisch } \\
\text { altprovenzalisch } \\
\text { arabisch }\end{array}$ & griech. & griechisch \\
\hline Art. & Artikel & halem. & hochalemannisch \\
\hline aruss. & altrussisch & hd. & hochdeutsch \\
\hline asächs. & altsächsisch & hebr. & hebräisch \\
\hline asorb. & altsorbisch & hess. & hessisch \\
\hline atschech. & alttschechisch & holl. & holländisch \\
\hline Attr. & Attribut & holst. & holsteinisch \\
\hline attr. & attributiv & hpreuß. & hochpreußisch \\
\hline avenez. & altvenezianisch & Hs. & Handschrift \\
\hline bair. & bairisch & idg. & indogermanisch \\
\hline bair.-öst. & bairisch-österreichisch & ieur. & indoeuropäisch \\
\hline balt. & baltisch & Imp. & Imperativ \\
\hline berl. & berlinisch & Ind. & Indikativ \\
\hline böhm. & böhmisch & Inf. & Infinitiv \\
\hline brandenb. & brandenburgisch & Instr. & Instrumentalis \\
\hline burg. & burgundisch & $\begin{array}{l}\text { Interj. } \\
\text { intrans. }\end{array}$ & $\begin{array}{l}\text { Interjektion } \\
\text { intransitiv }\end{array}$ \\
\hline & & ir. & irisch \\
\hline Dat. & Dativ & isl. & isländisch \\
\hline Dekl. & Deklination & it. & italisch \\
\hline Dem. & Demonstrativum & ital. & italienisch \\
\hline Dim. & Diminutivum & & \\
\hline dt. & deutsch & jidd. & jiddisch \\
\hline
\end{tabular}


kan.

Kaus.

kelt.

$\mathrm{Kj}$.

klass.

Komp.

Konj.

Konjug.

Kons.

krimgot.

kroat.

kslaw.

Kt.

langob.

Lat./lat.

lett.

lit.

liv.

lomb.

lothr.

lux.

m.

magy.

mähr.

märk.

Mask.

mbair.

md.

mengl.

meckl.

mfries.

mfrk.

mfrz.

mgriech.

mhd.

mlat.

mnd.

mnl.

mrhein.

mslfrk.

n.

nalem.

nass.

nd.

nengl.

nfries.

nfrk.

nfrz.

ngriech

nhd.

$\mathrm{nl}$.

nmärk.

nnd.

nnl.

nnord.

nnsächs.

nobd.

nodt.

Nom. kanadisch

Kausativ

keltisch

Konjunktiv

klassisch

Komparativ

Konjunktion

Konjugation

Konsonant

krimgotisch

kroatisch

kirchenslawisch

Karte

langobardisch

Latein/lateinisch

lettisch

litauisch

livländisch

lombardisch

lothringisch

luxemburgisch

maskulin

magyarisch

mährisch

märkisch

Maskulinum

mittelbairisch

mitteldeutsch

mittelenglisch

mecklenburgisch

mittelfriesisch

mittelfränkisch

mittelfranzösisch

mittelgriechisch

mittelhochdeutsch

mittellateinisch

mittelniederdeutsch

mittelniederländisch

mittelrheinisch

moselfränkisch

Neutrum

niederalemannisch

nassauisch

niederdeutsch

neuenglisch

neufriesisch

niederfränkisch

neufranzösisch

neugriechisch

neuhochdeutsch

niederländisch

nordmärkisch

neuniederdeutsch

neuniederländisch

neunordisch

nordniedersächsisch

nordoberdeutsch

nordostdeutsch

Nominativ norw.

npr.

nrddt

nrhein.

nsächs

nschwed.

nsorb.

Num.

obd.

obfr.

Obj.

obl.

obsorb.

odt.

ofäl.

ofrk.

ogerm.

ohalem.

omd.

ON

ond.

oobd.

opom.

orhein.

osächs.

oslaw.

osorb.

öst.

Part.

part.

Pass.

Perf.

pfälz.

Pl.

Plquperf.

polab.

poln.

pom.

pomoran.

Pos.

port.

Präp.

Präs.

Prät.

Prät.-Präs.

Pron.

prov.

rät.

rätorom.

refl.

rib.

rom.

rotw.

rhfrk.

russ.

saarl.

sächs.

sbair. norwegisch

niederpreußisch

norddeutsch

niederrheinisch

niedersächsisch

neuschwedisch

niedersorbisch

Numerus

oberdeutsch

oberfränkisch

Objekt

obliquus

obersorbisch

ostdeutsch

ostfälisch

ostfränkisch

ostgermanisch

osthochalemannisch

ostmitteldeutsch

Ortsname

ostniederdeutsch

ostoberdeutsch

ostpommersch

oberrheinisch

obersächsisch

ostslawisch

ostsorbisch

österreichisch

Partizip

partizipal

Passiv

Perfekt

pfälzisch

Plural

Plusquamperfekt

polabisch

polnisch

pommersch

pomoranisch

Positiv

portugiesisch

Präposition

Präsens

Präterium

Präterito-Präsens

Pronomen

provenzalisch

rätisch

rätoromanisch

reflexiv

ribuarisch

romanisch

rotwelsch

rheinfränkisch

russisch

saarländisch

sächsisch

südbairisch 
schott.

schw.

schwäb.

schwed.

schweiz.

sdt.

serb.

serbokroat.

sfrk.

$\mathrm{Sg}$.

skand.

slaw.

slow.

smk.

sodt.

sofrk.

sorb.

span.

splat.

spmhd.

srhfrk.

sslaw.

st.

St.

Subj.

Subst.

Sup.

swdt. schottisch

schwach flektierend

schwäbisch

schwedisch

schweizerdeutsch

süddeutsch

serbisch

serbokroatisch

südfränkisch

Singular

skandinavisch

slawisch

slowenisch

südmärkisch

südostdeutsch

südostfränkisch

sorbisch

spanisch

spätlateinisch

spätmittelhochdeutsch

südrheinfränkisch

südslawisch

stark reflektierend

Stamm

Subjekt

Substantiv

Superlativ

südwestdeutsch trans.

thür.

tir.

tschech.

ugr.

ukrain.

ung.

urgerm.

uridg.

urslaw.

urverw.

venez.

vorahd.

vpom.

vulglat.

wdt.

wend.

westf.

wgerm.

whalem.

wslaw.

wmd.

wnd.

wobd.

Wz. transitiv

thüringisch

tirolisch

tschechisch

ugrisch

ukrainisch

ungarisch

urgermanisch

urindogermanisch

urslawisch

urverwandt

venezianisch

voralthochdeutsch

vorpommersch

vulgärlateinisch

westdeutsch

wendisch

westfälisch

westgermanisch

westhochalemannisch

westslawisch

westmitteldeutsch

westniederdeutsch

westoberdeutsch

Wurzel 
